\title{
Questionamentos em Aulas de Química: Um Estudo Comparativo da Prática Pedagógica em Diferentes Contextos Sociais
}

\section{Questions in the Chemistry Class: A Comparative Study of Pedagogic Practices in Different Social Contexts}

\author{
Rivaldo Lopes da Silva \\ Geovânia Moreira Souza \\ Brasil \\ Bruno Ferreira dos Santos \\ Brasil \\ Brasil
}

Este trabalho apresenta e discute os resultados de uma pesquisa sobre o discurso em salas de aula de Química e que teve como objeto os questionamentos do professor e dos estudantes. Baseada no conceito de enquadramento oriundo da teoria sobre o discurso pedagógico de Basil Bernstein e nos tipos de iniciação de Hugh Mehan, a pesquisa teve como objetivo estudar a influência dos contextos sociais sobre a prática pedagógica de professores de Química e sua manifestação sobre seus questionamentos em sala de aula. Por meio da análise, comparamos o posicionamento do professor durante os episódios de questionamento e os tipos de iniciação apresentados nas perguntas do docente e de seus estudantes. A metodologia da pesquisa foi baseada em um estudo de caso, e os dados foram coletados em duas escolas urbanas de Ensino Médio situadas em diferentes contextos socioeconômicos. Os resultados mostraram diferenças no posicionamento do professor tanto em relação às respostas dos alunos quanto em relação às suas perguntas em ambas as escolas e também diferenças no posicionamento do professor em relação às perguntas dos alunos entre as escolas. Também com base nos resultados de nossa análise, identificamos uma relação entre o tipo de iniciação e os graus de enquadramento da prática pedagógica. Atribuímos estes resultados à diferença no ritmo das práticas pedagógicas entre as escolas e ao modo de controle do professor frente aos alunos das duas escolas. Tais diferenças geraram diferentes cadeias de interação e perguntas com níveis conceituais distintos.

Palavras-chave: Ensino de Química; discurso em sala de aula; questionamentos.

This article presents and discusses the findings of a research on the discourse in chemistry classes that was focused on the questions of the teacher and the students. Based on the concept of framing derived from Basil Bernstein's theory of pedagogical discourse and Hugh Mehan's initiation types, the research aimed to study the influence of social contexts on the pedagogical practice of Chemistry teachers and its manifestation on 
their questions in the classroom. Through the analysis, we compared the position of the teacher during the questioning episodes and the types of initiation presented in the questions asked by the teacher and his students. The research methodology was based on a case study, and the data were collected in two urban secondary schools located in different socioeconomic contexts. The results showed differences in the teacher's position in relation to the both students' answers and in relation to their questions in both schools, and also differences in the teacher's position regarding the students' questions between the schools. Based on the results of our analysis, we identified a relationship between the type of initiation and the degrees of framing of the pedagogical practice. We address these findings with the difference in the pace of the pedagogical practices between the schools and the mode of teacher's control in front of the students of the two schools. These differences generated different chains of interaction and questions with different conceptual levels.

Keywords: Chemistry teaching; classroom discourse; questionings.

\section{Introdução}

Estudos sobre as interações discursivas entre professores e alunos em sala de aula revelam a existência de padrões estabilizados de comunicação, caracterizados principalmente por meio das perguntas dos professores e respostas dos alunos, normalmente acompanhadas por uma avaliação, pelo professor, das respostas (Mehan, 1979; Lemke, 1997). Este particular padrão de comunicação, identificado como I-R-A (Iniciação-Resposta-Avaliação), sinaliza a centralidade das perguntas para o discurso de sala de aula. $\mathrm{O}$ reconhecimento deste padrão como o dominante no discurso em sala de aula situou os questionamentos como um destacado objeto da pesquisa sobre a caracterização dos estilos de ensino e de suas relações com a aprendizagem na investigação em Educação.

Para a Educação em Ciências, a importância dos questionamentos se relaciona com o fato de que elaborar boas perguntas é um dos elementos chave para o desenvolvimento científico (Bachelard, 1996), e este elemento deve estar presente no ensino, se quisermos que as disciplinas escolares introduzam os estudantes nas formas do pensamento e investigação das diferentes Ciências. Segundo Aguiar Jr., Mortimer e Scott (2006) "focalizar o questionamento em detrimento das respostas é uma forma de desenvolver uma compreensão da natureza da ciência e do pensar científico" (p. 12). $\mathrm{O}$ uso dos questionamentos no ensino de Ciências permite, entre outras coisas, que o professor oriente e influencie o pensamento dos alunos (van Zee, \& Minstrell, 1997). Além disso, as perguntas também constituem um dispositivo capaz de promover e estimular as interações em sala de aula. De acordo com a perspectiva sociocultural para a educação científica, a aprendizagem se dá pela aquisição da linguagem e das formas de pensamento características de uma dada disciplina, e é promovida principalmente por intermédio das interações discursivas entre professores e alunos (Quílez-Pardo, 
2016). Esta perspectiva sobre a aprendizagem nos leva a considerar o diálogo - e nele, os questionamentos em particular - em sala de aula como um importante objeto de pesquisa em educação científica.

Este destaque em torno das interações discursivas para os processos de ensino e aprendizagem em Ciências também nos informa sobre a necessidade da promoção de aulas mais dialógicas entre professores e estudantes. Como o padrão I-R-A é aquele considerado como dominante no discurso em sala de aula, o estudo sobre as perguntas, tanto de professores como dos alunos, pode servir como um indicador da natureza deste discurso. Por meio das perguntas, por exemplo, pode-se tentar promover, junto aos aprendizes, níveis de cognição mais elevados de conhecimento científico (Chin, 2013; Tobin, 1987). O engajamento dos alunos nas situações de diálogo iniciadas pelos questionamentos é fundamental para o estabelecimento da dialogia, algo ainda raro nas aulas de Ciências (Magalhães, Mortimer, \& Silva, 2016). Entretanto, o protagonismo do professor na condução do diálogo e na elaboração das perguntas também pode inibir uma prática mais dialógica (Tytler, \& Aranda, 2015). Este fenômeno tem sido explicado, em parte, pela peculiar natureza dos questionamentos no diálogo em sala de aula, que se distancia das situações cotidianas vividas pelos alunos. Neste ambiente, o professor faz perguntas para as quais ele já conhece a resposta, o que pode causar desconfiança e desconforto entre os estudantes (Jackson, 2002).

A iniciativa do diálogo por meio de questionamentos pelos estudantes depende da criação em sala de aula de um clima favorável, em que suas iniciativas sejam escutadas e respondidas, criando uma atmosfera de acolhimento e estímulo à sua participação neste contexto. De acordo com Specht, Ribeiro e Ramos (2017),

Práticas pedagógicas que estimulem os estudantes a fazerem perguntas em aula partindo de seu contexto e de sua realidade podem aprimorar os modelos explicativos iniciais para pensamentos mais desenvolvidos, incorporando uma visão científica e mais complexa, de modo a ampliar a compreensão desses modelos e desencadear perguntas com perfis mais voltados a processos de investigação (p. 227).

Entretanto, na maior parte das aulas de Ciências, o que se nota é a participação de poucos estudantes, e a grande maioria permanece recolhida em silêncio.

Nas literaturas internacional e brasileira têm sido publicadas diversas pesquisas que investigam os questionamentos de professores e alunos. Seus autores buscam caracterizá-los e verificar sua relação com o engajamento no diálogo e com a aprendizagem conceitual dos estudantes em uma variedade de situações de ensino e de estratégias didáticas, como no laboratório escolar ou por meio da aprendizagem baseada em problemas (Specht, Ribeiro, \& Ramos, 2017; Andrade, \& Mozzer, 2016; Silva, 2015; Kawalkar, \& Vijapurkar, 2013; Erdogan \& Campbell, 2008; Schein \& Coelho, 2006; Chin, 2006; Bleicher, Tobin, \& McRobbie, 2003). Também se encontram pesquisas que abordam a presença dos questionamentos em livros e manuais escolares (Torres, Almeida, \& Vasconcelos, 2015).

Em investigação realizada previamente, foi observada uma notável diferença na 
comunicação entre professores e alunos em aulas de Química: um mesmo professor que dava aulas em escolas cujos estudantes pertenciam a contextos socioeconômicos diferentes entre si lograva obter uma participação muito maior no diálogo em sala de aula com os alunos provenientes de meios economicamente mais favorecidos do que com aqueles pertencentes às classes populares (Souza, 2015). Como hipótese inicial para a explicação desta diferença, assumimos a possibilidade da influência do contexto social sobre a prática pedagógica do professor em questão.

Usando os dados obtidos nesta pesquisa anterior, procuramos analisar as perguntas do professor e de seus alunos, com o objetivo de compreender, em um estudo comparativo, se a natureza destas perguntas e de seus desdobramentos no diálogo estaria favorecendo ou limitando a participação dos estudantes nas interações discursivas. Partindo deste objetivo inicial, este artigo apresenta e discute os resultados da análise da prática pedagógica de um professor de Química, orientada pelas seguintes questões de pesquisa:

Como se distribuem os tipos de perguntas do professor e dos alunos nos dois contextos escolares?

Há variação no controle da comunicação pelo professor entre os dois contextos durante os questionamentos?

Há relação observável entre o controle da comunicação pelo professor e o nível cognitivo das perguntas?

\section{Quadro teórico}

A relação entre a educação e a sociedade é abordada pela Sociologia da Educação, que tem como um de seus objetivos principais investigar e compreender como os bens culturais são distribuídos, via educação, entre os diferentes segmentos sociais. Este ramo da Sociologia também se interessa por entender de que forma essa distribuição contribui para a reprodução das desigualdades - educacionais e sociais - no interior de uma sociedade. No estudo destes fenômenos, a teoria sobre o discurso pedagógico de Basil Bernstein se destaca ao relacionar os microcontextos da educação, como o espaço da sala de aula, com os contextos sociais mais amplos. Por meio dos conceitos de classificação e enquadramento, Bernstein propõe verificar como as categorias sociológicas de poder e de controle, respectivamente, atuam sobre as práticas pedagógicas desenvolvidas no interior das escolas. Para este autor, a distribuição do poder e do controle se origina na divisão social do trabalho e, por meio desta, influencia as relações entre as classes sociais. De acordo com sua teoria, o poder e o controle se traduzem em princípios de comunicação na relação pedagógica. O discurso pedagógico, por sua vez, é o dispositivo institucionalizado que distribui a consciência, a mensagem e a voz, sob as diversas orientações assumidas pelo poder e pelo controle no interior de uma dada sociedade.

A classificação, segundo Bernstein, reflete o isolamento entre categorias: sujeitos, discursos e espaços. Quanto maior for o isolamento, mais forte será o grau de classificação entre estas categorias, o que contribui para o reconhecimento, pelos sujeitos, dos diferentes 
contextos em que estão situados. $\mathrm{O}$ enquadramento reflete o controle que um sujeito que ocupa uma posição mais alta em uma relação hierárquica é capaz de estabelecer na comunicação entre ele e os demais sujeitos presentes em uma determinada relação social e em um contexto particular. Na prática pedagógica, quanto maior for o controle sobre os elementos do discurso (seleção, sequência, ritmo e critérios de avaliação), mais forte será o grau de enquadramento; quando os sujeitos que ocupam posições inferiores em uma relação hierárquica assumem algum controle sobre os elementos do discurso, há um enfraquecimento do grau de enquadramento. Bernstein argumenta que

O controle exercido pelo professor determina quem pode falar, que voz se pode ouvir, o quê se pode dizer e, deste modo, qual identidade permanece seletivamente legitimada. O controle do professor regula a medida com a qual as competências e práticas comunicativas das famílias e da comunidade podem ser eficazes na sala de aula ou regula, melhor, quais competências comunicativas e quais práticas podem resultar eficazes (1988, p. 135).

$\mathrm{O}$ enquadramento se relaciona com as regras de realização, e possibilita aos sujeitos, quando de posse destas regras, produzirem o texto legítimo para cada contexto em que estão situados e são interpelados (Bernstein, 2001).

A combinação entre diferentes graus de classificação e de enquadramento dá origem a diversas modalidades de prática pedagógica, desde as mais "tradicionais" até as mais "progressivas", e configura diferentes tipos de códigos pedagógicos. Para que os aprendizes sejam bem sucedidos eles devem ser capazes de adquirir a orientação particular do código associado a uma determinada prática pedagógica. Isso significa que o sucesso ou o êxito implica na aquisição, pelos aprendizes, tanto das regras de reconhecimento como das regras de realização, para que possam produzir o texto adequado ou legítimo para o contexto em que se situam, como pode ser o caso de uma aula de Química. Texto aqui se refere a qualquer produção, material ou não, concebida pelos sujeitos. De acordo com Morais (2002),

A compreensão do desempenho diferenciado em Ciências requer uma análise dos discursos pedagógicos específicos como um conjunto de regras que regulam a transmissão/aquisição do conhecimento científico. O discurso pedagógico referese não somente aos conteúdos científicos e competências a serem transmitidas, mas também à sua transmissão e avaliação - isto é, ele se refere ao que é transmitido, como é transmitido e também às realizações do estudante que são consideradas legítimas ( $\mathrm{p}$. 560, tradução nossa).

Segundo a teoria de Bernstein (2001), os princípios do controle estabelecem as relações sociais que, por sua vez, definem os princípios de comunicação, caracterizados pelo enquadramento. O contexto comunicativo dependerá não somente do enquadramento, mas também da classificação, pois o código pedagógico vem definido por ambos. Além disso, Bernstein diferencia duas modalidades no discurso pedagógico: um discurso regulador e um discurso instrucional. $\mathrm{O}$ primeiro se relaciona com questões de ordem. de conduta e de identidade, e é caracterizado por meio das regras 
hierárquicas, as quais definem os papéis dos sujeitos no seio de uma relação social. $\mathrm{O}$ segundo vem dado pelas regras discursivas e transmite os conteúdos e competências na prática pedagógica. De acordo com o sociólogo, o discurso instrucional está subsumido no discurso regulador, que é o discurso dominante.

Bernstein distingue também linguagens diferentes entre a teoria e a pesquisa, uma linguagem interna que descreve as relações dentro da teoria, e uma externa, que permite descrever o que está fora da teoria (isto é, o mundo empírico). Portanto, uma análise amparada em Bernstein necessita a construção desta linguagem externa que permitirá utilizar sua teoria junto ao referencial empírico (Moore, \& Muller, 2003). A linguagem externa utilizada neste trabalho foi desenvolvida por Morais e Neves (2001) e adaptada às nossas questões de pesquisa. Segundo estas autoras, tal linguagem é derivada principalmente da linguagem interna da teoria de Bernstein, e é capaz de estabelecer uma relação dialética entre a teoria e o referente empírico.

Esta abordagem sociológica para a pesquisa em ensino de Ciências tem como enfoque as relações sociais que constituem a atividade pedagógica. Tais relações envolvem os sujeitos, os discursos, e as agências e espaços. No caso específico desta pesquisa, objetivamos investigar as relações entre professor e aluno, por meio das regras hierárquicas, que podem ser analisadas considerando tanto a classificação como o enquadramento. Como estamos interessados particularmente nos questionamentos, ou seja, na comunicação, a investigação se orienta pelo estudo dos princípios de comunicação caracterizados pelo enquadramento. As regras podem ser explícitas (quando assumem um grau de enquadramento forte) e implícitas (quando assumem um grau de enquadramento fraco). Quando as regras são explícitas, as relações de poder entre transmissor e adquirentes são muito claras; quando são implícitas, se torna mais difícil distinguir o transmissor do adquirente. As regras hierárquicas, portanto, dizem respeito exclusivamente à relação entre sujeitos (Bernstein, 2001).

$\mathrm{O}$ estudo dos questionamentos, por sua vez, tem se baseado em diferentes tipologias (Torres, Almeida, \& Vasconcelos, 2015). O critério principal usado para a distinção entre os tipos de questionamentos é o nível de demanda ou exigência conceitual e/ou cognitiva das perguntas. Uma das tipologias empregadas para a análise dos questionamentos em sala de aula é a classificação dos tipos de iniciação proposta por Hugh Mehan (1979), um sistema que inclui quatro tipos de perguntas e que foi baseado em um estudo etnográfico desenvolvido por este autor. De acordo com Mehan, estes tipos são:

1. Iniciação de escolha: "a elicitação de escolha demanda ao respondente que concorde ou discorde com uma afirmação feita pelo perguntador" (Mehan, 1979, p. 44). Para Mortimer, Massicame, Buty, e Tiberghien (2007, p. 66), "além da escolha entre sim ou não, temos também a escolha entre duas possibilidades diferentes". Neste tipo de iniciação, encontramos perguntas como: 'É o flúor não é?' 'Mas não são os elétrons não ligantes?' 'Aí vai acrescentar o nome da base?'

2. Iniciação de produto: "a elicitação de produto demanda ao respondente uma 
resposta factual como um nome, um lugar, uma data, uma cor" (Mehan, 1979, p. 44). De acordo com Mortimer et al. (2007, p. 67),

Esse tipo de iniciação normalmente toma a forma de uma questão do tipo "o que" ou "qual", que elicita um substantivo ou um adjetivo denotando um agente, um evento, um processo nominalizado, uma propriedade, etc.

Para esta categoria encontramos perguntas do tipo: 'O que é um fosgênio?' 'São quantas geometrias?' 'Professor, serragem é o que mesmo?'

3. Iniciação de processo: “a elicitação de processo demanda a opinião ou interpretação do respondente" (Mehan, 1979, p. 45). De acordo como Mortimer et al. (2007, p. 66), este tipo de iniciação é formada pelas "questões do tipo 'por que,' 'como' ou 'o que acontece', que elicitam um processo específico que deve ser descrito ou explicado, normalmente, por uma frase completa”. As iniciações encontradas deste tipo podem ser perguntas como: 'Porque ficou sulfato de magnésio?' 'Como assim em equilíbrio?'

4. Iniciação de metaprocesso:

(...) um quarto tipo de elicitação demanda aos estudantes que sejam reflexivos sobre o processo de estabelecer conexões entre elicitações e respostas. Essas elicitações são chamadas de metaprocesso porque pedem ao estudante para formular e expressar as bases de seu pensamento (Mehan, 1979, p. 46 citado em Mortimer et al., 2007, p. 67).

Para esta categoria encontramos perguntas do tipo: 'E se ficar dentro de um lugar sem oxigênio?' 'Como você pode justificar?'.

Por meio da aproximação entre um marco teórico proveniente da Sociologia da Educação e outro oriundo da Etnografia Interacional nos propusemos a investigar a prática pedagógica no ensino de Química, relacionando a intersecção entre os padrões culturais de participação no discurso em sala de aula e o conhecimento disciplinar científico. Esta intersecção tem estado ausente na literatura existente, conforme observação feita por Lee (2005). Este artigo tem como objetivos analisar os tipos de perguntas do professor e de seus estudantes nos dois contextos de sala de aula investigados, contrastar seus resultados e analisar o controle do professor nos episódios das perguntas, por meio dos graus de enquadramento. Seu propósito é estabelecer correlações entre os resultados obtidos por meio das diferentes análises e, por meio destas, identificar a manifestação da influência do contexto social sobre a prática pedagógica de Química. Com esta pesquisa espera-se contribuir para o entendimento sobre a participação dos aprendizes no discurso em sala de aula desta disciplina, considerando como variável principal o contexto social dos estudantes.

\section{O caminho metodológico}

Esta pesquisa está definida como um estudo de caso instrumental. Tal perspectiva de estudo de caso "permite procedimentos tanto indutivo como dedutivos, e se orienta tanto em captar os aspectos subjetivos como objetivos da vida social" (Neiman, \& Quaranta, 2007, p. 222). Apoiados nas definições de estudo de caso de Robert Yin (2005), 
Neiman e Quaranta argumentam que:

A amostra é definida em função dos interesses temáticos e conceituais, e os casos podem ser selecionados segundo diversos critérios, por exemplo, a partir de determinadas condições que transformam o caso em um fenômeno único ou o constituem em uma expressão pragmática de um problema social. O caso é definido como um sistema delimitado em tempo e espaço de atores, relações e instituições sociais onde se busca dar conta da particularidade do mesmo no marco da sua complexidade (Neiman, \& Quaranta, 2007, p. 219-220, tradução nossa).

Os métodos e técnicas para a produção dos dados para esta pesquisa foram: a observação das aulas de um professor de Química em duas escolas, uma particular e outra pública, o registro das aulas por meio de gravadores de áudio e de caderno de campo, e a transcrição dos áudios. Os registros em caderno de campo foram utilizados para a contextualização dos dados transcritos. As aulas foram observadas por uma unidade letiva (aproximadamente dois meses) em cada unidade escolar. Um questionário socioeconômico foi aplicado a ambas as turmas a fim de se obter o perfil dos alunos de forma a caracterizá-los quanto ao contexto social ao qual pertenciam. Os resultados deste questionário confirmaram que os estudantes pertenciam a estratos socioeconômicos diferenciados, quando contrastamos os dados referentes à escolarização e a profissão dos pais (Souza, 2015). Vale ressaltar que nossa entrada no campo somente ocorreu após a aprovação do projeto de pesquisa que deu origem a esta investigação, pelo Comitê de Ética de nossa universidade.

As escolas que serviram de cenário da pesquisa situam-se em regiões urbanas diferentes. A escola pública está situada em um bairro periférico e atende, prioritariamente, estudantes da própria comunidade em que está localizada. A escola privada está em uma região central, e sua clientela é proveniente de vários bairros da cidade. A classe observada na escola pública possuía 44 alunos, enquanto aquela na escola privada possuía somente 32. A faixa etária dos alunos era equivalente entre as turmas observadas. O professor de Química era jovem, com apenas cinco anos de docência no momento das observações, licenciado e mestre em Química pela mesma instituição, uma universidade pública do interior da Bahia. Duas entrevistas semiestruturadas foram realizadas após as observações em cada escola, objetivando conhecer as orientações didáticas e pedagógicas escolhidas pelo professor com respeito aos diferentes grupos de alunos e às escolas em que ensinava no momento de nossas observações. Os dados destas entrevistas foram usados de forma complementar nas interpretações dos resultados das análises das práticas pedagógicas.

As aulas foram ministradas em turmas do primeiro ano do Ensino Médio e corresponderam aos conteúdos de estrutura atômica, ligações e reações químicas. As observações totalizaram 48 aulas, sendo $24 \mathrm{em}$ cada escola. Às transcrições dos áudios das aulas, em conjunto com sua contextualização por meio dos registros em caderno de campo, seguiu-se sua fragmentação em episódios. Altet (2000) define um episódio como uma unidade particular do discurso. "Um episódio começa por uma expressão que desencadeia uma troca verbal sobre um determinado assunto e termina quando 
finaliza a discussão do assunto" (Altet, 2000, p. 66), e pode ser constituído de uma ou várias interações sobre o assunto ou ocasiões. $\mathrm{O}$ episódio se compõe, assim, de várias comunicações, com um início, um meio e uma conclusão.

Para a análise dos questionamentos, selecionamos todos os episódios em que verificamos a presença de perguntas do professor e/ou dos alunos. No caso das perguntas do professor, usamos como critério de escolha as interações que produziam resposta por parte de algum aluno. Isto eliminou as perguntas retóricas e aquelas que não foram respondidas. Os questionamentos selecionados foram quantificados e analisados de acordo com a tipologia de Mehan para as iniciações e também de acordo com dois instrumentos chamados de indicadores, relacionados com as regras hierárquicas na relação professor-alunos, para a determinação dos graus de enquadramento. Um dos indicadores empregados nesta análise foi adaptado do grupo ESSA ${ }^{1}$ e o outro foi elaborado para esta pesquisa de acordo com os nossos objetivos. Estes indicadores são apresentados na próxima sessão deste artigo.

\section{Resultados e discussão}

Nos dados apresentados a seguir, chama-se PU a escola pública e PR a escola privada. A Figura 1 apresenta a quantidade total de questionamentos - do professor e dos estudantes - observados nos episódios das duas turmas que foram observadas.

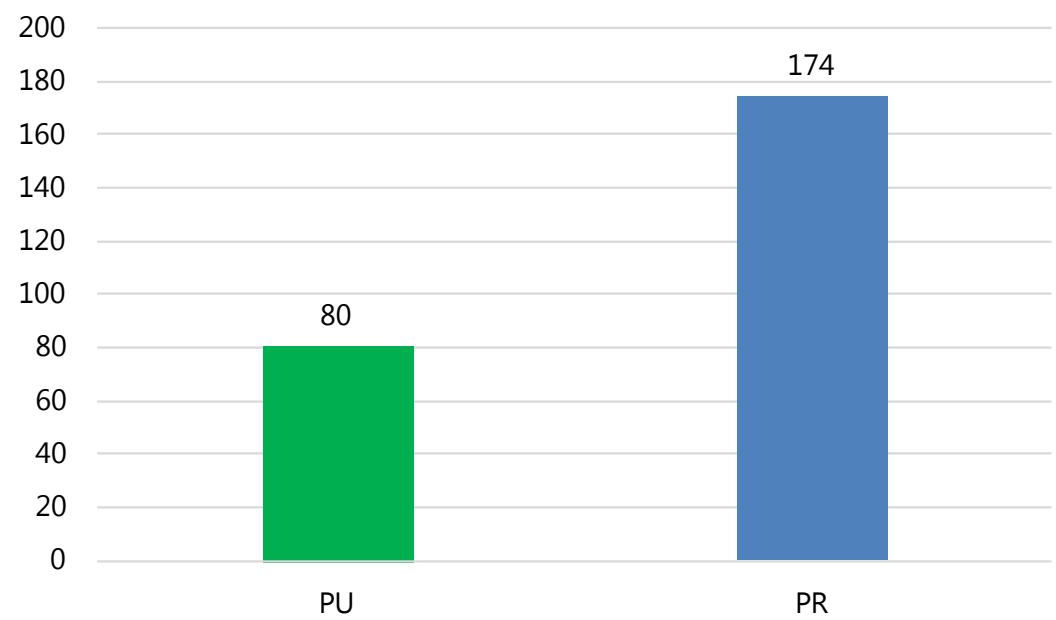

Figura 1.Total de questionamentos nas turmas das escolas pública e privada

Fonte: Elaboração própria

A Figura 1 evidencia que, para uma mesma quantidade de aulas, ocorreu um pouco mais que o dobro de questionamentos na escola privada em relação à escola pública. Esta tendência se mantém quando separamos os questionamentos do professor e dos alunos nas duas escolas, conforme ilustrado pela Figura 2, embora a quantidade de questionamentos elaborados pelos estudantes da escola pública seja inferior à metade daquele encontrado na escola privada. Este resultado também confirma o protagonismo 1 Grupo ESSA: Estudos Sociológicos de Sala de Aula, vinculado à Universidade de Lisboa e coordenado pelas pesquisadoras Ana Maria Morais e Isabel Pestana Neves. 
do professor neste tipo de diálogo, sendo este superior na escola pública, uma vez que nesta o número de seus questionamentos representa aproximadamente três vezes o dos estudantes (na escola privada esta proporção é aproximadamente duas vezes). Isto pode indicar que os alunos da escola privada se sentem mais à vontade para questionar do que os da escola pública. Os números também refletem uma quantidade superior de interações entre professor e alunos, via questionamentos, na escola privada.

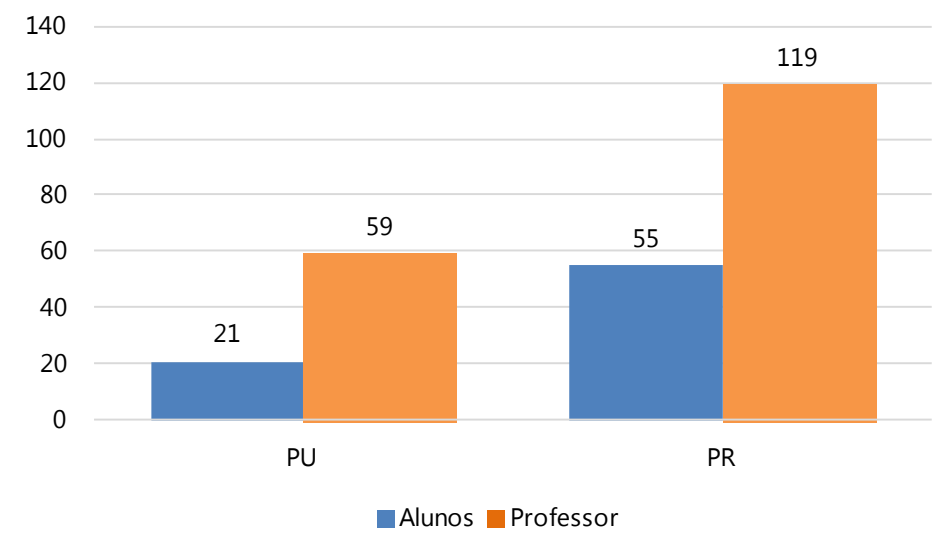

Figura 2. Total de questionamentos de alunos e professor por escola

Fonte: Elaboração própria

Esta diferença quantitativa entre os questionamentos nas duas escolas pode ser compreendida considerando-se o fator tempo: o professor dispõe de apenas duas aulas por semana (50 minutos cada aula) na escola pública, enquanto na escola privada sua carga horária é o dobro. Isto impõe à prática pedagógica na escola pública um ritmo mais intenso:

Com um ritmo muito intenso o tempo se torna escasso e isto regula os exemplos, as ilustrações e os relatos que facilitam a aquisição; determina que perguntas se possam demandar e em que quantidade; (...) Ademais, um ritmo intenso tende a reduzir as intervenções orais do aluno e a privilegiar, pelo contrário, a fala do professor, e isto é algo que os estudantes chegam a considerar preferível dado que o tempo é escasso para a mensagem pedagógica oficial. Assim, permanece afetada a própria estrutura profunda da comunicação pedagógica (Bernstein, 1988, p. 138).

Sugerimos que esta desigualdade no tempo disponível para a comunicação pedagógica em sala de aula entre as duas escolas é um dos principais fatores que produz as diferenças, não somente na quantidade absoluta de questionamentos do professor e dos alunos, mas também a diferente proporção entre as perguntas do professor e seus alunos em cada turma observada.

Os questionamentos também foram classificados de acordo com a tipologia proposta por Mehan. Quanto às perguntas do professor em ambas as escolas, os resultados da análise dos tipos de iniciação são mostrados nas Figuras 3 e 4. 


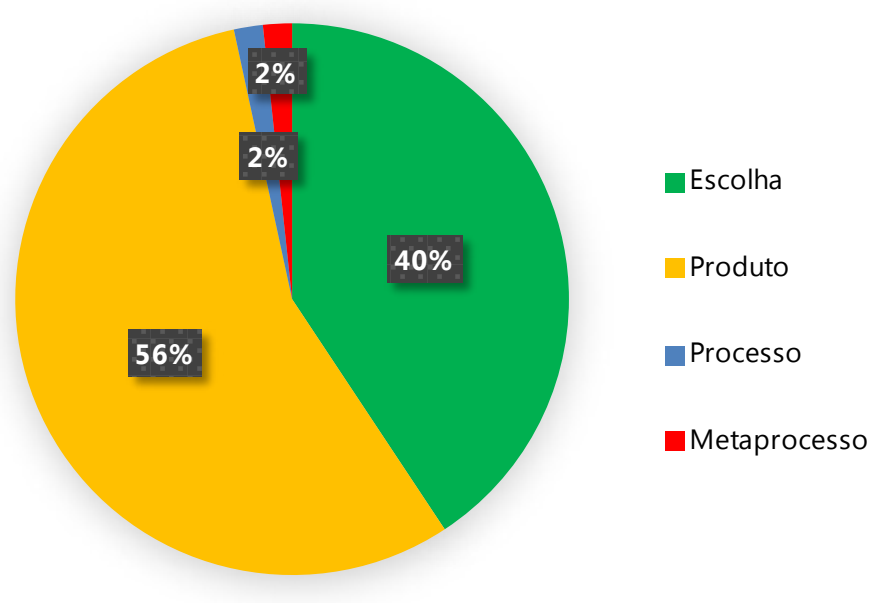

Figura 3. Tipos de iniciação do professor/ Escola pública

Fonte: Elaboração própria

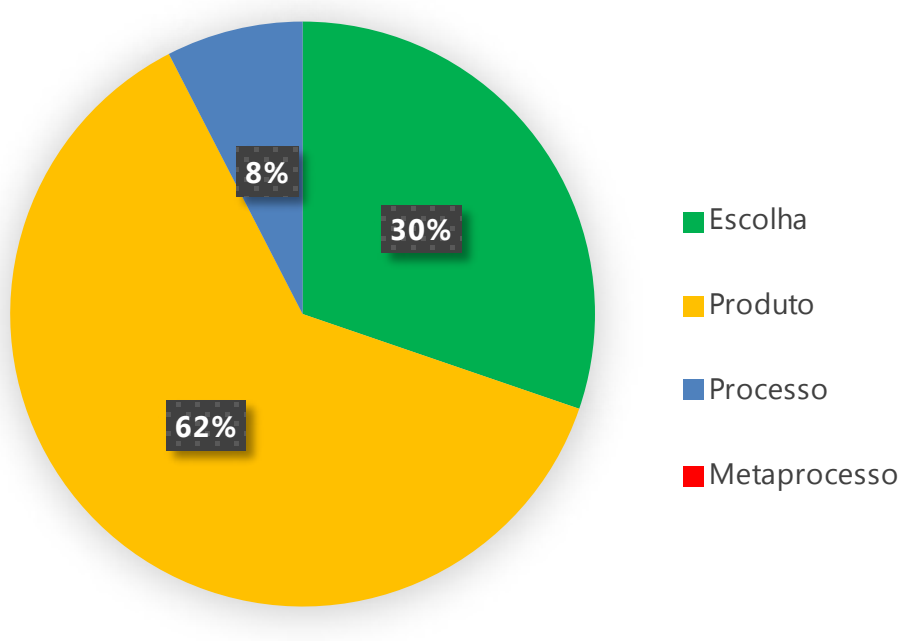

Figura 4. Tipos de iniciação do professor/ Escola privada

Fonte: Elaboração própria

Os gráficos apresentados nas Figuras 3 e 4 mostram que a iniciação de produto predomina nas duas turmas (62\% e 56\%, respectivamente, na escola privada e na escola pública). Isto significa um diálogo em sala de aula cujos questionamentos são constituídos prioritariamente de perguntas fechadas, que exploram a aprendizagem dos nomes dos conceitos e os resultados de cálculos numéricos, muitas vezes sob a forma do preenchimento de lacunas no discurso do professor. Seguem a estas as iniciações de escolha, com uma menor frequência na escola privada comparada com a escola pública (30\% e 40\%). Esta ligeira diferença abre espaço para as iniciações de processo na escola privada, que alcançam $8 \%$ do total de questionamentos do professor e somente $2 \%$ na escola pública. Entretanto, seus questionamentos em ambas as turmas são constituídos principalmente por tipos de iniciação de menor demanda conceitual, com poucos 
exemplos de perguntas que solicitam a opinião ou a interpretação dos estudantes. Isto é ilustrado por meio de fragmentos de episódios das duas turmas observadas apresentados no Figura 5.

\begin{tabular}{|c|c|}
\hline PU: Aula sobre reações químicas & PR: Aula sobre geometria molecular \\
\hline $\begin{array}{l}\text { Prof.: Doze, qual a relação do doze com o } \\
\text { seis no experimento anterior? (Iniciação de } \\
\text { produto) } \\
\text { Aluna: É o dobro! } \\
\text { Prof.: É o dobro... ele utilizou o dobro de gás } \\
\text { nitrogênio e ele utilizou o que de dezoito pra } \\
\text { trinta e seis? Qual é a relação? (Iniciação de } \\
\text { produto) } \\
\text { Aluna: O dobro } \\
\text { Prof.: Isso o dobro ele utilizou }\end{array}$ & $\begin{array}{l}\text { Prof.: Não ( ) ... quando você pensa em quatro } \\
\text { nuvens eletrônicas ao redor do átomo central, } \\
\text { você não pensa em triângulo, vai pensar em uma } \\
\text { disposição vai pensar em uma disposição o quê? } \\
\text { Que arranjo eu vou ter? (Iniciação de produto) } \\
\text { aluno: É... } \\
\text { Prof.: que arranjo? } \\
\text { Aluno: Um losango } \\
\text { Professor: Vai ficar um o quê? } \\
\text { Aluno: Tipo um losango } \\
\text { Professor: Tipo um losango }\end{array}$ \\
\hline
\end{tabular}

Figura 5. Fragmentos de episódios com questionamentos do professor em PU e PR

Fonte: Elaboração própria

Para a análise do controle da comunicação pelo professor e sua relação com os tipos de iniciação dos questionamentos, elaboramos um indicador que evidencia o posicionamento do professor perante as respostas apresentadas pelos alunos. Este indicador permite verificar como tal posicionamento estimula o desenvolvimento de um diálogo mais prolongado, ou com mais desdobramentos, do que aquele verificado no padrão I-R-A. A Figura 6 apresenta o indicador proposto e os respectivos graus de enquadramento atribuídos às diferentes situações de ensino.

\begin{tabular}{|c|c|c|c|c|}
\hline Indicador & $\mathrm{E}^{++}$ & $\mathrm{E}^{+}$ & $\mathrm{E}^{-}$ & $\mathrm{E}^{--}$ \\
\hline $\begin{array}{l}\text { Pergunta do } \\
\text { professor }\end{array}$ & $\begin{array}{l}\text { O professor } \\
\text { sempre avalia } \\
\text { a resposta } \\
\text { do aluno } \\
\text { confirmando-a } \\
\text { ou } \\
\text { rejeitando-a. }\end{array}$ & $\begin{array}{l}\text { Ao escutar a } \\
\text { resposta do aluno, } \\
\text { o professor faz } \\
\text { novas perguntas e/ } \\
\text { ou considerações } \\
\text { para, em conjunto } \\
\text { com o aluno, } \\
\text { confirmar ou } \\
\text { rejeitar sua } \\
\text { resposta inicial. }\end{array}$ & $\begin{array}{l}\text { O professor } \\
\text { escuta a resposta } \\
\text { e estimula os } \\
\text { demais alunos a } \\
\text { se manifestarem } \\
\text { para, em } \\
\text { seguida, avaliar, } \\
\text { confirmando } \\
\text { ou rejeitando as } \\
\text { respostas. }\end{array}$ & $\begin{array}{l}\text { Após estimular os } \\
\text { demais alunos a } \\
\text { se manifestarem, } \\
\text { o professor escuta } \\
\text { suas respostas } \\
\text { e provoca uma } \\
\text { discussão entre eles } \\
\text { para que os mesmos } \\
\text { possam chegar a um } \\
\text { consenso sobre a } \\
\text { resposta correta. }\end{array}$ \\
\hline
\end{tabular}

Figura 6. Descrição do indicador usado na avaliação do grau de enquadramento das perguntas do professor.

Os resultados da análise dos episódios selecionados por meio deste indicador para cada escola são mostrados nas Figuras 7 e 8. 


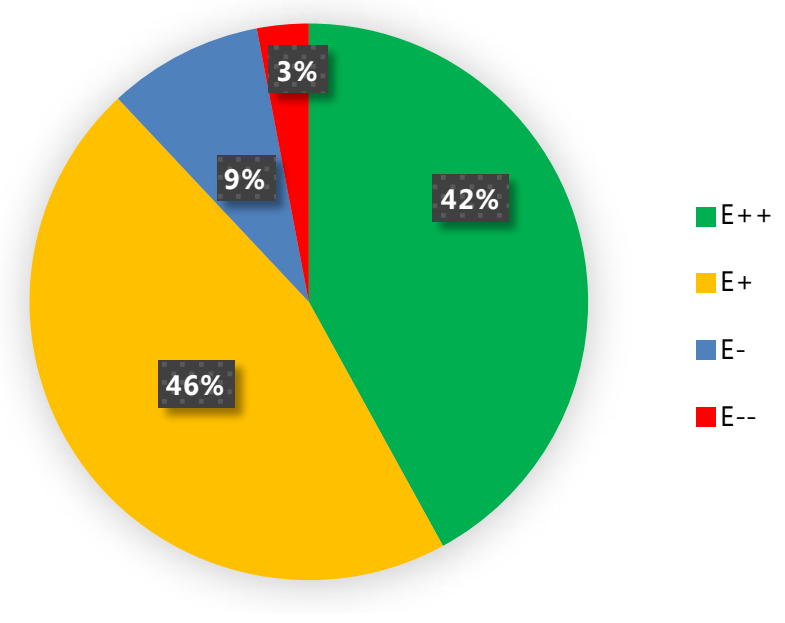

Figura 7. Graus de enquadramento para as perguntas do professor na escola pública Fonte: Elaboração própria

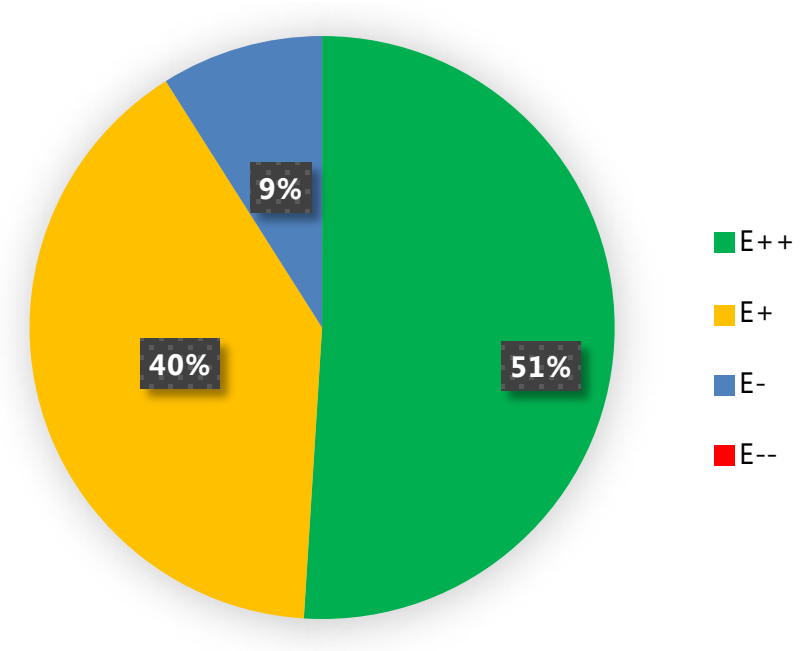

Figura 8. Graus de enquadramento perguntas do professor na escola privada

Fonte: Elaboração própria

Os resultados desta análise revelaram uma maior tendência para um grau de enquadramento muito forte $\left(\mathrm{E}^{++}\right)$do professor na escola privada $(51 \%)$ comparado com aquele observado na escola pública $(42 \%)$. O grau de enquadramento muito fraco ( $\mathrm{E}^{-}$ -), por exemplo, só foi observado neste último cenário. Estes resultados, em princípio, revelariam uma prática pedagógica levemente mais favorável às interações e ao diálogo para além do padrão I-R-A na escola pública do que na escola privada. No entanto, como a maioria de suas iniciações em ambas as escolas são do tipo de produto, esta diferença observada nos graus de enquadramento pode indicar uma maior dificuldade dos alunos da escola pública na aprendizagem dos nomes dos conceitos, ou mesmo na execução de cálculos numéricos simples, como pode ser visto nos fragmentos de 
episódios mostrados na Figura 9.

\begin{tabular}{|l|l|}
\hline PU: Aula sobre leis químicas & PR: Aula sobre geometria molecular \\
\hline & Prof.: Foi esta a minha pergunta... eu tenho \\
Prof.: O que é átomo?... (Iniciação de produto) & $\begin{array}{l}\text { quantas nuvens eletrônicas em volta do átomo } \\
\text { central? Ao redor do átomo central... eu tenho }\end{array}$ \\
Aluno: Moléculas & quantas? (Iniciação de produto) \\
Prof.: Moléculas, o quê mais? & Aluna: Três \\
Aluno: Pequena partícula & Prof.: Três ... e estas três nuvens eletrônicas são \\
Prof.: Pequena partícula, perfeito & ligantes? (Iniciação de escolha) \\
$\left(\mathbf{E}^{+}\right)$ & Aluno: Duas são e uma não \\
& $\left(\mathbf{E}^{++}\right)$ \\
\hline
\end{tabular}

Figura 9. Fragmentos de episódios de questionamentos do professor em PU e PR

Fonte: Elaboração própria

Na etapa seguinte de nossa análise, associamos os tipos de iniciação das perguntas do professor com seus respectivos graus de enquadramento. Os resultados desta análise aparecem nas Figuras 10 e 11.

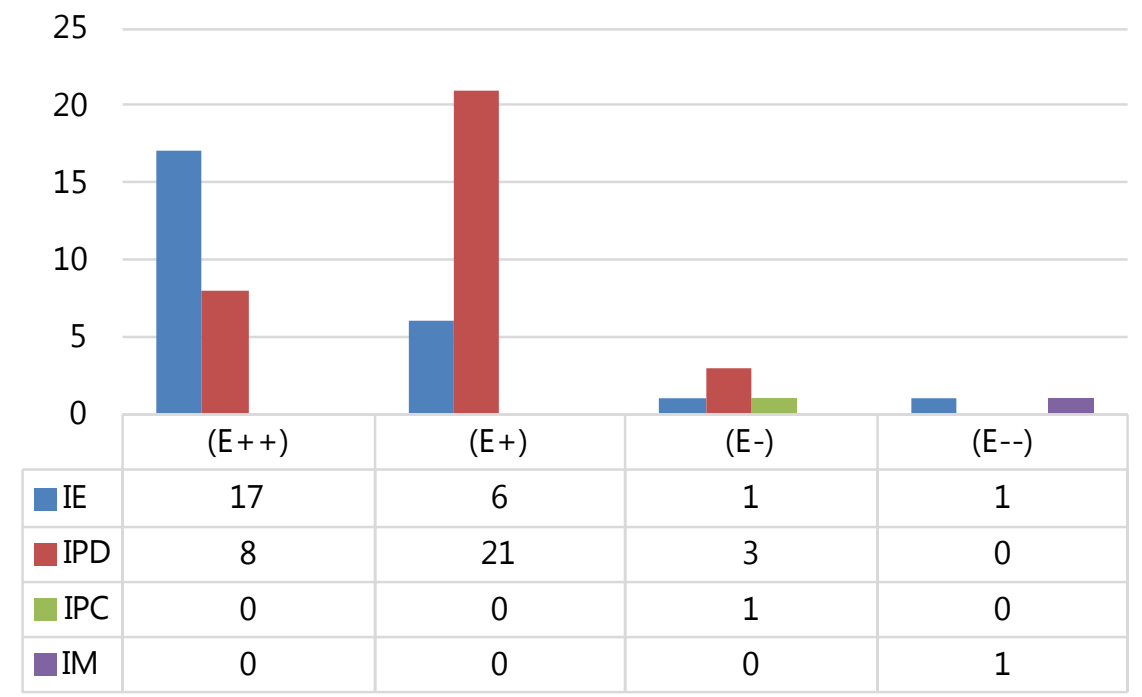

Figura 10. Relação entre o grau de enquadrameno e os tipos de iniciação do professor na escola pública

Fonte: Elaboração própria 


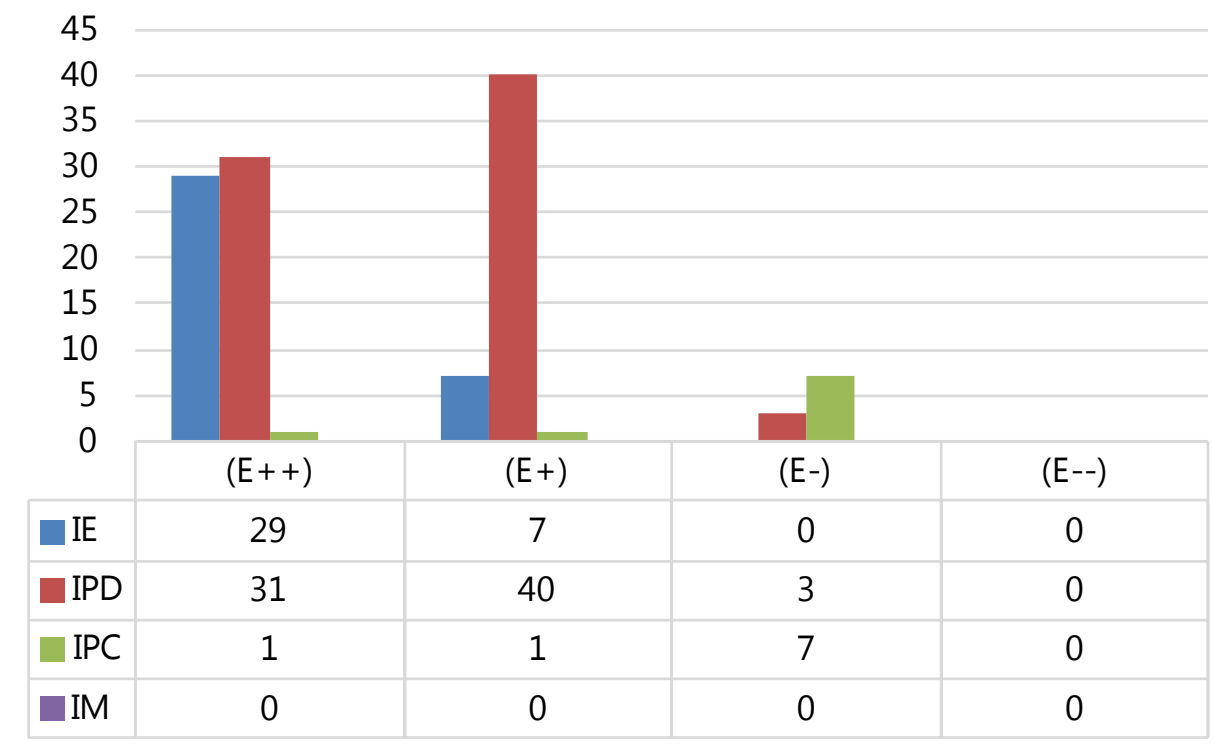

Figura 11. Relação entre o grau de enquadramento e os tipos de iniciação do professor na escola privada

Fonte: Elaboração própria

A maior associação entre as iniciações de produto com um grau de enquadramento forte na escola pública fica evidenciada por quando se observa as Figuras 10 e 11, pois na escola privada esta associação abrangeu pouco mais da metade para este tipo de iniciação, enquanto na escola pública representou quase três quartos do total. Os resultados desta análise também mostraram que os poucos episódios observados com iniciações de processo e de metaprocesso em ambas as turmas promoveram um enfraquecimento do grau de enquadramento na prática pedagógica. Isso significa que as perguntas com uma maior demanda conceitual conduziram, na maioria das vezes, a um diálogo mais prolongado, com mais interações professor-aluno. Isso pode ser visto nos fragmentos apresentados no Figura 12, em episódios das duas escolas. Como os episódios de iniciações destes dois tipos foram um pouco mais frequentes na escola privada, esta associação entre os tipos de iniciação e os graus de enquadramento mais fracos foi mais visível para os questionamentos nesta escola. 


\begin{tabular}{|c|c|}
\hline PU: Aula sobre reações químicas & PR: Aula sobre geometria molecular \\
\hline $\begin{array}{l}\text { Prof.: Fica normal ok! Fica normal? Você } \\
\text { acha que desce, por que você acha que } \\
\text { desce? ... Por que você acha que desce? } \\
\text { (Iniciação de processo) } \\
\text { Aluna: Não acho que desce não, fica normal } \\
\text { (risos) } \\
\text { Prof.: Fica normal? } \\
\text { Aluno: Ah eu acho que fica em equilíbrio } \\
\text { Prof.: Fica em equilíbrio! ... } \\
\text { (E) }\end{array}$ & $\begin{array}{l}\text { Prof.: Tetraedro é um poliedro de (...) um poliedro } \\
\text { regular onde você vai ter todos os ângulos internos } \\
\text { iguais, todas as áreas faciais iguais por que LM? Por/ } \\
\text { (Iniciação de processo) } \\
\text { Aluno: Sempre vai ser? } \\
\text { Prof.: Por que as nuvens eletrônicas são todas } \\
\text { de mesma natureza: são todas o quê? Idênticas... } \\
\text { tranquilo isto? Ok, próxima molécula amônia NH } \\
\text { () determinar a geometria e arranjo da amônia, } \\
\text { primeiro passo é o quê? } \\
\text { Alunos: Os elétrons } \\
\text { Prof.: Calcular os elétrons de valência ... o } \\
\text { nitrogênio? Nitrogênio? Cinco mais hidrogênio um } \\
\text { vezes três, um vezes três ... três mais cinco? ... oito. E } \\
\text { agora eu faço o quê?? } \\
\text { Alunos: Divide por dois } \\
\text { Prof.: Oito dividido por dois, eu tenho que ter quatro } \\
\text { pares de elétrons } \\
\text { (E-) }\end{array}$ \\
\hline
\end{tabular}

Figura 12. Fragmentos de episódios de questionamentos do professor em PU e PR

Fonte: Elaboração própria

Na Figura 13, apresentamos a frequência dos tipos de iniciação para as perguntas dos alunos da escola pública. Não foram observadas iniciações de metaprocesso nas perguntas dos alunos nesta escola.

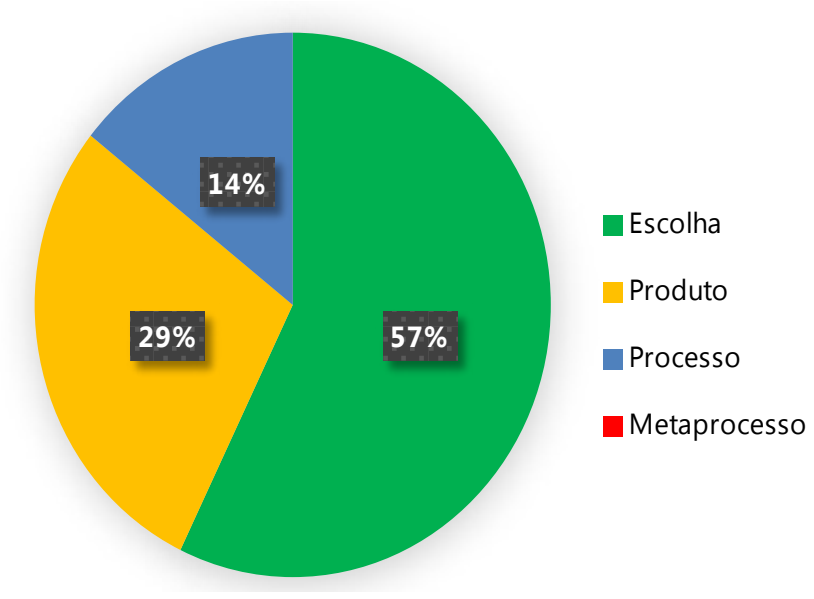

Figura 13. Tipos de iniciação dos alunos da escola pública

Fonte: Elaboração própria

A Figura 14 apresenta os resultados desta análise para a escola privada, na qual 
foram encontrados todos os tipos de iniciação.

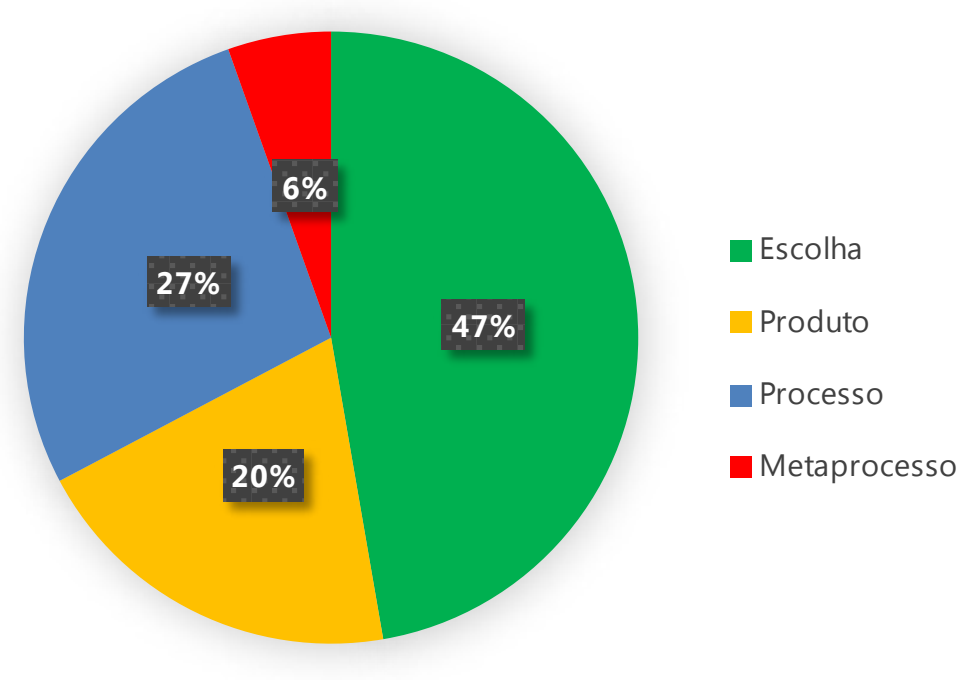

Figura 14. Tipos de iniciação dos alunos da escola privada

Fonte: Elaboração própria

A Figura 15 traz exemplos de episódios envolvendo iniciações de escolha (a de maior frequência) e de processo dos alunos em ambas as escolas. A ausência ou a pequena frequência de iniciações de metaprocesso coincide com a observação de Mehan (1979), de que este tipo de iniciação é o mais raro nas interações entre professores e alunos, quando comparado com os demais tipos de iniciação. Entretanto, chama a atenção a menor frequência de iniciações de maior demanda cognitiva (processo e metaprocesso) entre os estudantes da escola pública comparada com a observada na escola privada ( $14 \%$ e $33 \%$, respectivamente). Se considerarmos que estes últimos realizaram mais questionamentos durantes as aulas (ver Figura 3), as interações entre estes e o professor apresentam mais episódios envolvendo questões abertas, que solicitam explicações e opiniões, enquanto a ampla maioria das perguntas dos estudantes da escola pública ( $86 \%$ do total) representa questões simples e fechadas. De acordo com Aguiar Jr., Mendonça e Silva (2007),

As dificuldades dos estudantes em formular boas questões podem estar ligadas tanto a fatores cognitivos - dificuldades em identificar informações contraditórias ou em reconhecer conceitos que são necessários para dar continuidade ao raciocínio exigido quanto a fatores sociais - receio de parecer tolo perante colegas e professor, dificuldade em tomar um turno de fala ou mudar o tema em pauta em uma aula, entre outros (p.3). 


\begin{tabular}{|c|c|}
\hline \multicolumn{2}{|l|}{ Iniciação de escolha } \\
\hline PU: Aula sobre funções inorgânicas & PR: Aula sobre geometria molecular \\
\hline $\begin{array}{l}\text { Prof.: Muda a terminação o prefixo é sulf. } \\
\text { Não é sulfu, é prefixo sulf mais a terminação } \\
\text { ato. U não é prefixo é um radical da palavra } \\
\text { Aluna: Aí vai acrescentar o nome da base? } \\
\text { Prof.: Não entra a base }\end{array}$ & $\begin{array}{l}\text { Aluno: Oh LM, mas não são os elétrons não } \\
\text { ligantes? } \\
\text { Prof.: Sim } \\
\text { Aluno: Então você meio que exclui }\end{array}$ \\
\hline \multicolumn{2}{|l|}{ Iniciação de Processo } \\
\hline PU: Aula sobre composição da matéria & PR: Aula sobre reações químicas \\
\hline $\begin{array}{l}\text { Aluno: Como é o nome? E como assim? } \\
\text { Prof.: Leucito e Demócrito, Leucipo é um, e } \\
\text { Demócrito é outro. Lançaram esta hipótese } \\
\text { antes de Cristo, apenas também como } \\
\text { pensamento filosófico, nada comprovado } \\
\text { experimentalmente lançaram essa ideia } \\
\text { como? Eles trabalhando com tijolos, } \\
\text { acidentalmente deixou um tijolo cair no } \\
\text { chão. Quando o tijolo caiu no chão, se } \\
\text { dividiu em duas partes. Aí um deles pegou } \\
\text { uma das partes e dividiu em mais duas, } \\
\text { pegava esta outra parte quebrava e dividia } \\
\text { em mais duas, aí foi fragmentando a matéria } \\
\text { até não conseguir mais fragmentar e aí } \\
\text { chegou numa parte muito pequena que eles } \\
\text { não conseguiram dividir. Daí eles falaram: } \\
\text { toda matéria é constituída por esta parte } \\
\text { indivisível que eu chamo de átomo... }\end{array}$ & $\begin{array}{l}\text { Aluno: Como assim doou? } \\
\text { Prof.: Como assim doou? OH agora só tenho O } \\
\text { em toda a espécie química } \mathrm{C}_{6} \mathrm{H}_{5} \mathrm{OH} \mathrm{C}_{6} \mathrm{H}_{5} \mathrm{O}^{-} \text {. Por } \\
\text { que perdeu o próton perdeu a espécie } \mathrm{H}_{\text {para }} \\
\text { formar este } \mathrm{O}^{-} \text {. Então o que acontece? O outros/ os } \\
\text { outros você entendeu M? Pois é, qual a diferença } \\
\text { destes compostos pro de cima? Este daqui é um } \\
\text { aníon este aqui também é um aníon, ( (apontando } \\
\text { para as espécies representadas no quadro branco)) } \\
\text { aqui ele tinha que ganhar um, aqui ele tinha que } \\
\text { ganhar dois. Bom, é por que ele perdeu uma } \\
\text { espécie química, ele perdeu este próton aqui, } \mathrm{H}^{+} \text {. } \\
\text { Agora olhe isso aqui, } \mathrm{O}-\text {, e olhe para isto aqui, } \mathrm{OH} \text {, } \\
\text { significa o que? }\end{array}$ \\
\hline
\end{tabular}

Figura 15. Fragmentos de episódios de questionamentos dos alunos em PU e PR

Fonte: Elaboração própria

Também analisamos os graus de enquadramento das práticas pedagógicas para as situações de perguntas dos alunos. Para isto, empregamos um indicador por meio do qual procuramos evidenciar o controle da comunicação nos intercâmbios professoralunos nos episódios em que os alunos fazem perguntas. A Figura 16 apresenta a descrição do indicador e seus respectivos graus de enquadramento, que variam entre muito forte $\left(\mathrm{E}^{++}\right)$e muito fraco $\left(\mathrm{E}^{--}\right)$. 


\begin{tabular}{|l|l|l|l|l|}
\hline Indicador & $\mathrm{E}^{++}$ & $\mathrm{E}^{+}$ & $\mathrm{E}^{-}$ & $\mathrm{E}^{--}$ \\
\hline $\begin{array}{l}\text { Perguntas dos } \\
\text { alunos }\end{array}$ & $\begin{array}{l}\text { O professor } \\
\text { ignora as } \\
\text { perguntas. }\end{array}$ & $\begin{array}{l}\text { O professor } \\
\text { responde } \\
\text { diretamente aos } \\
\text { alunos. }\end{array}$ & $\begin{array}{l}\text { O professor } \\
\text { responde aos } \\
\text { alunos, formulando } \\
\text { outras perguntas e } \\
\text { fornecendo algumas } \\
\text { informações } \\
\text { adicionais. }\end{array}$ & $\begin{array}{l}\text { O professor } \\
\text { responde } \\
\text { aos alunos, } \\
\text { promovendo a } \\
\text { discussão entre } \\
\text { vários alunos. }\end{array}$ \\
\hline
\end{tabular}

Figura 16. Descrição de indicador usado na avaliação do grau de enquadramento das perguntas dos alunos.

$\mathrm{Na}$ escola pública, a prática pedagógica só apresentou dois graus de enquadramento, classificados como forte $\left(\mathrm{E}^{+}\right)$e fraco $\left(\mathrm{E}^{-}\right)$. A Figura 17 ilustra a distribuição da frequência destes graus nos episódios analisados. A predominância foi do grau de enquadramento forte, ou seja, o professor respondia diretamente aos alunos na maioria de seus questionamentos. A predominância deste grau de enquadramento significa que são criadas poucas oportunidades de se expandir ou prolongar o diálogo para outras formas, além dos encadeamentos simples pergunta-resposta, no caso das iniciativas dos alunos.

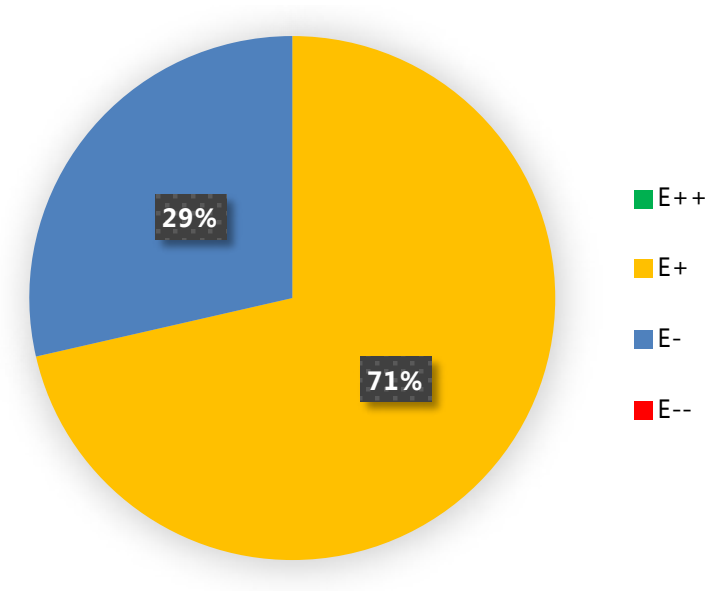

Figura 17. Graus de enquadramento para Perguntas dos alunos na Escola Pública

Fonte: Elaboração própria

A análise dos episódios de questionamentos dos alunos na escola privada revela um cenário um pouco diferente, em que são observados todos os graus de enquadramento, conforme representado na Figura 18. A maior parte destes é de grau fraco $\left(\mathrm{E}^{-}\right)$, acompanhado pelo grau forte $\left(\mathrm{E}^{+}\right)$, ficando os demais com aproximadamente uma quinta parte dos episódios. Neste caso, ao responder as perguntas dos alunos, o professor costumava fornecer mais informações além daquilo que havia sido solicitado, ou, ainda, prolongava o diálogo com novas perguntas, gerando novas cadeias de interação entre ele e os alunos. Ao considerar os graus de enquadramento predominantes nas duas 
escolas, conclui-se que o posicionamento do professor foi diferente entre elas, uma vez que ele respondia de modo mais direto aos estudantes da escola pública do que aos da escola privada. Isto é ilustrado pelos fragmentos de episódios mostrados na Figura 19.

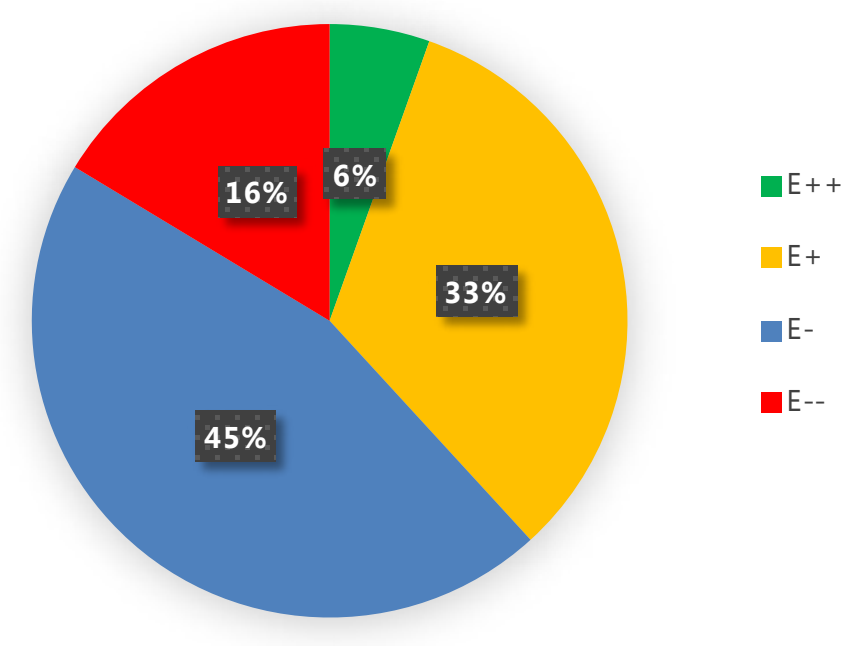

Figura 18. Graus de enquadramento para as perguntas dos alunos na Escola Privada

Fonte: Elaboração própria

\begin{tabular}{|l|l|}
\hline PU: Aula sobre reações químicas & PR: Aula sobre geometria molecular \\
\hline & Aluno: Qual a polaridade? (Iniciação de produto) \\
& Prof.: Bacana qual a polaridade deste daqui? \\
& Alunos: Este aí? / esse é apolar/ oh professor soma os \\
& vetores? (Iniciação de escolha) \\
Aluno: Professor serragem é o que & Prof.: Todos os vetores \\
mesmo? (Iniciação de produto) & Aluno: Então é apolar \\
Prof.: Pó de serra & Prof.: Então é apolar? Vamos ver: flúor com bromo, \\
$\left(\mathbf{E}^{+}\right)$ & quem é mais eletronegativo? Flúor... a densidade \\
& eletrônica também está apontando para onde? ... para \\
& os elétrons não ligantes ok? Bom, aí você pensa em \\
& vetores sendo anulados para que você possa/ \\
& $($E) $)$ \\
\hline
\end{tabular}

Figura 19. Fragmentos de episódios para graus de enquadramentos em PU e PR

Fonte: Elaboração própria

De acordo com Morais (2002), um enquadramento mais fraco quanto às regras hierárquicas cria um contexto no qual os estudantes se sentem mais à vontade para questionar, discutir e compartilhar suas ideias. Isto, por sua vez, permite ao professor fortalecer o enquadramento no nível dos critérios de avaliação, o que significa fornecer 
aos estudantes as regras por meio das quais eles são capazes de produzir o texto legítimo no contexto escolar. Segundo esta mesma autora, o modo de controle exercido pelo professor sob um enquadramento mais forte para as regras hierárquicas é imperativo/ posicional, com maior separação entre o rol do professor e dos alunos. Por outro lado, sob um enquadramento mais fraco, o professor utiliza um controle pessoal, o que contribui para a aquisição, pelos estudantes, dos critérios necessários para se avaliar e corrigir sua própria resposta. Ao comparar nossos resultados, verificamos que o modo de controle do professor nos dois contextos investigados difere de forma significativa, pois na escola pública sua postura mais frequente frente aos questionamentos dos alunos era imperativa/posicional enquanto na escola privada era majoritariamente, um controle pessoal.

Para verificar as relações entre o controle da comunicação exercido pelo professor e os tipos de iniciação apresentados pelos alunos, analisamos a tendência do grau de enquadramento para cada tipo de iniciação encontrado nas duas escolas. Nosso objetivo era verificar se os diferentes tipos de iniciação se associavam com diferentes graus de controle, com enquadramentos mais fracos produzindo diferentes cadeias de interação e perguntas com maior nível conceitual. Os resultados desta análise mostram que as iniciações de processo e de metaprocesso se produziram nos graus de enquadramento mais fraco, conforme mostrado nas Figuras 20 e 21.

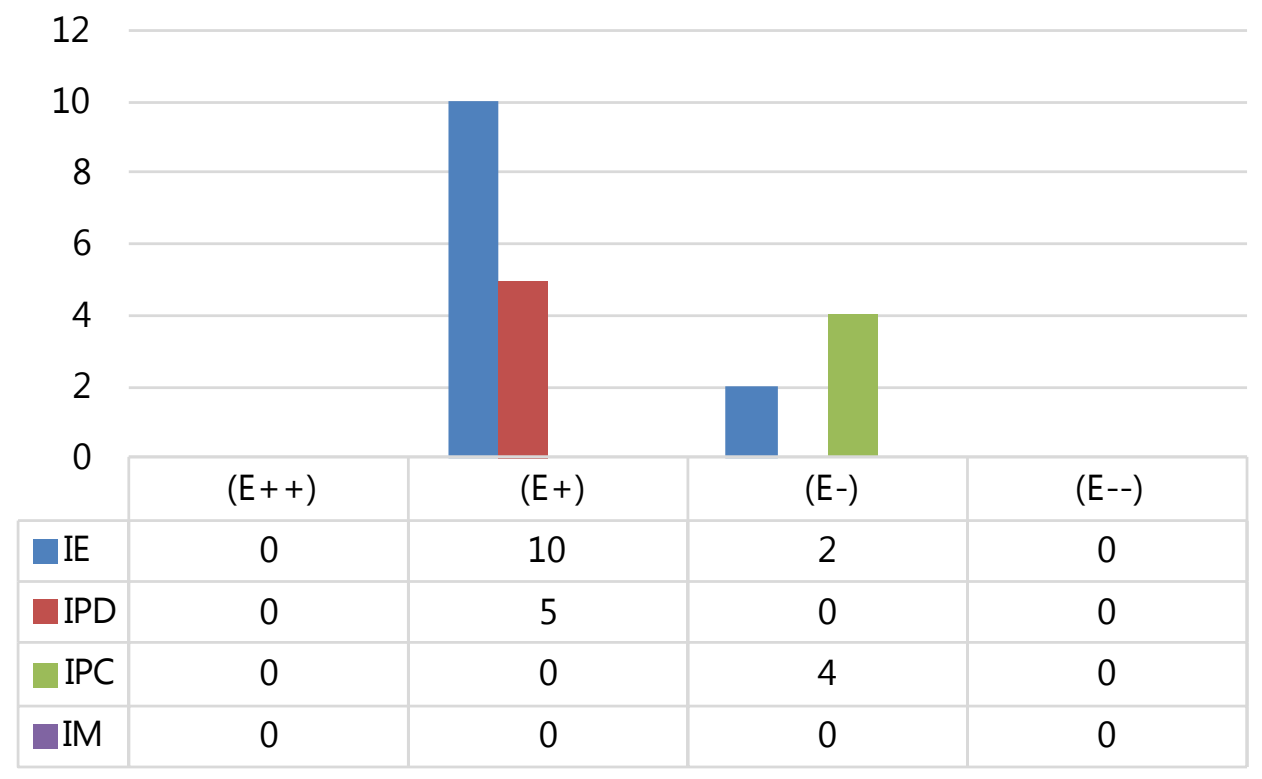

Figura 20. Relação entre o grau de enquadramento do professor e os tipos de iniciação dos alunos na escola pública

Fonte: Elaboração própria 


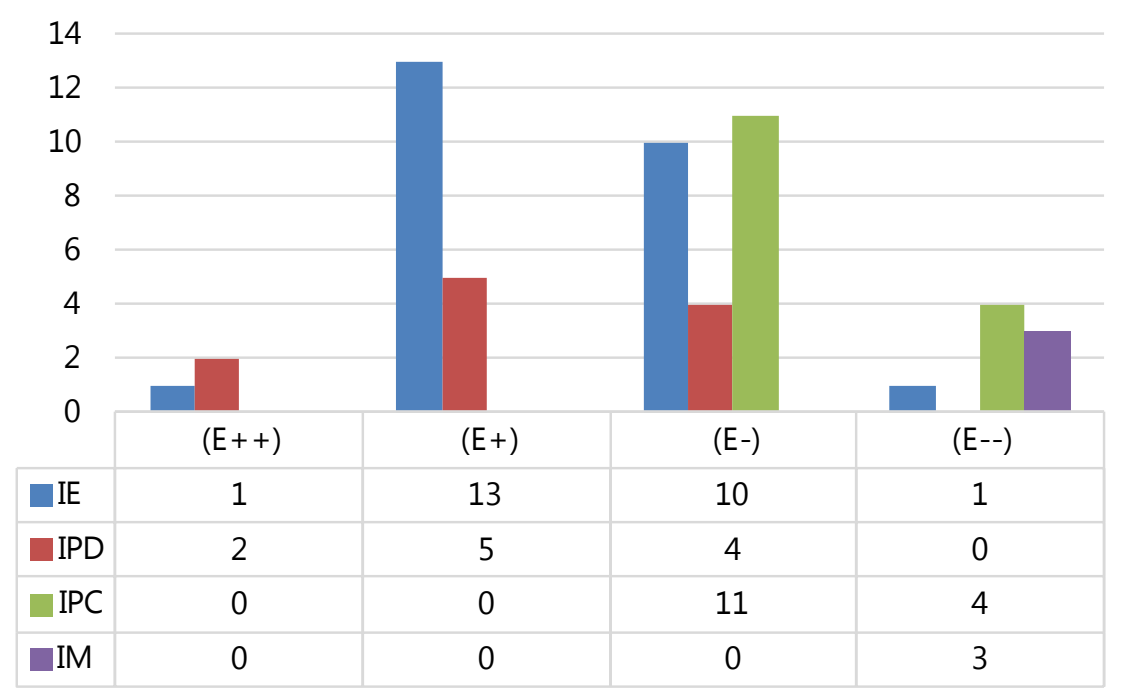

Figura 21. Relação entre o grau de enquadramento do professor e os tipos de iniciação dos alunos na escola privada

Fonte: Elaboração própria

Os resultados desta análise evidenciam, em ambas as escolas, uma associação entre as iniciações de processo e de metaprocesso com os graus de enquadramento fraco e muito fraco. Isto significa que as perguntas que elicitam opiniões e interpretações do professor, ou seja, aquelas de maior demanda conceitual, geraram cadeias de interação mais prolongadas, que enriqueciam o diálogo em sala de aula. Entretanto, na escola privada, diversos episódios com iniciações de produto, ou mesmo de escolha, produziram, com maior frequência, graus de enquadramento fraco e muito fraco, quando comparado com os resultados da escola pública. A Figura 22 apresenta dois exemplos de episódios com enquadramento fraco $\left(\mathrm{E}^{-}\right)$para ambas as escolas.

\begin{tabular}{|l|l|}
\hline PU: Aula sobre reações químicas & PR: Aula sobre geometria molecular \\
\hline $\begin{array}{l}\text { Aluna: Porque ficou sulfato de magnésio? } \\
\text { (Iniciação de processo) }\end{array}$ & $\begin{array}{l}\text { Aluno 2: Professor, pera aí. Isto aí não tá errado? } \\
\text { (Iniciação de escolha) }\end{array}$ \\
$\begin{array}{l}\text { Prof.: Qual é radical? O radical não é sulf, a } \\
\text { terminação não é ico? De ico muda para ato. }\end{array}$ & $\begin{array}{l}\text { Prof.: Ah ok... é um cátion né? Significa dizer que } \\
\text { ele perdeu o quê? Um elétron, nove menos um? } \\
\text { Olha lá: te mato te pico. }\end{array}$ \\
Aluno: Oito \\
Aluna: O magnésio é da base né? & Prof.: Oito dividido por dois \\
repete o magnésio é da base. Então você & Aluno: Quatro \\
Vamos praticar. & Prof.: Agora sim ...se fosse um ânion seria nove \\
(E-) & mais um, se fosse um cátion bivalente seria nove \\
& menos dois e assim por diante \\
\hline
\end{tabular}

Figura 22. Fragmentos de episódios de questionamentos dos alunos em PU e PR

Fonte: Elaboração própria 
No fragmento da escola privada, uma iniciação de demanda conceitual mais simples originou o mesmo posicionamento observado para uma iniciação de processo na escola pública.

As diferenças encontradas com respeito aos questionamentos dos estudantes nas duas escolas e ao posicionamento do professor no controle da comunicação foram mais acentuadas do que as observadas para os questionamentos do professor e seu posicionamento frente às respostas dos alunos. Novamente, o ritmo da prática pedagógica ajuda a compreender estas diferenças, pois de acordo com Bernstein (1988), um ritmo forte privilegia um código pedagógico lexical, em que respostas de uma única palavra ou frases curtas e que expressam fatos, habilidades ou operações individuais são mais típicas de escolas com alunos das classes sociais menos favorecidas, enquanto que um código pedagógico sintático, que expressa relações, processos e conexões pode ser mais típico de escolas com alunos de classe média, ainda que este autor ressalve que mesmo neste tipo de escola a participação dos alunos pode ser restringida.

Acreditamos também que as práticas comunicativas das famílias e das comunidades em que estes estudantes estão inseridos se originam a partir de hierarquias sociais distintas, com diferentes graus de classificação entre si, especialmente na relação entre pais e/ou responsáveis e filhos. Como o controle exercido pelo professor regula em que medida as competências e práticas comunicativas das famílias e das comunidades podem ser eficazes no discurso em sala de aula (Bernstein, 1988), as contribuições dos estudantes nas interações o posicionam de maneira diferenciada nas duas escolas em que leciona. Sua tendência a um controle mais imperativo na escola pública resultava em um comportamento mais passivo dos estudantes. Já na escola privada, um controle mais pessoal, baseado em relações menos assimétricas entre o professor e seus estudantes, produzia uma maior participação de seus estudantes.

\section{Considerações finais}

Neste artigo, analisamos os questionamentos de um professor de Química e de seus estudantes em aulas no Ensino Médio em duas escolas com perfis socioeconômicos diferentes. Os questionamentos foram analisados considerando duas dimensões: uma epistêmica, por meio dos tipos de iniciação, que nos forneceram uma classificação das perguntas relacionada com a exigência conceitual sobre o conhecimento disciplinar; e outra interacional, que nos proporcionou avaliar o posicionamento do professor frente aos questionamentos e respostas, por meio dos graus de enquadramento no discurso pedagógico. As diferenças mais significativas encontradas em nossa análise se relacionaram à quantidade dos questionamentos e aos tipos de perguntas dos estudantes e posicionamento do professor perante estas.

De um modo geral, as interações discursivas envolvendo questionamentos foram mais numerosas e envolveram mais tipos de iniciação na escola privada. O posicionamento do professor com respeito a suas próprias questões variou levemente entre as escolas, sendo um pouco mais favorável na escola pública ao considerarmos sua tendência para 
um enquadramento mais fraco em relação à escola privada. Isto pode ser explicado como efeito de uma maior dificuldade dos estudantes no aprendizado dos nomes dos conceitos e na execução de cálculos numéricos, o que levava o professor a estender as interações com novas perguntas quando ele se deparava com estas dificuldades. Já com respeito aos questionamentos dos estudantes, seu posicionamento variou de forma mais acentuada entre as escolas, apresentando graus de enquadramento mais fracos frente às perguntas na escola privada. Este posicionamento produzia padrões de interação que se afastavam do padrão típico I-R-A, especialmente quando as iniciações apresentavam maior demanda conceitual.

De acordo com a perspectiva sociocultural, as interações discursivas cumprem um papel fundamental para a aprendizagem das Ciências na sala de aula. O fato de estas interações serem mais promovidas junto a estudantes de um contexto social mais favorecido nos indica a influência deste contexto e sua manifestação sobre as práticas comunicativas nas relações pedagógicas. Nossos resultados, no entanto, não sinalizam qualquer espécie de déficit ou diferença cognitiva entre os estudantes deste professor, mas sim para distintas maneiras culturais de participação e de envolvimento no diálogo em sala de aula. Também não sugerimos que, de forma deliberada e consciente, este professor estabeleça práticas desiguais entre estes estudantes. Sobre este ponto, estamos de acordo com Morais e Miranda que argumentam que:

As escolas situadas em diferentes contextos socioeconômicos e culturais reproduzem estruturas organizacionais diferenciadas e formas de comunicação que são refletidas na sala de aula" (Morais, \& Miranda, 1996, p. 602).

Neste caso, os diferentes ritmos de sua prática pedagógica entre as duas escolas, que atribuímos à quantidade de aulas disponíveis por semana, se refletiam na qualidade dos questionamentos produzidos durante as interações discursivas.

Sobre o marco teórico-metodológico utilizado nesta pesquisa, consideramos que a justaposição entre a teoria do discurso pedagógico de Basil Bernstein e a tipologia de Hugh Mehan possibilitou uma análise da lógica interna, ou seja, dos princípios reguladores, da transmissão pedagógica e sua relação com o que é transmitido (Bernstein, 1988). Na análise apresentada neste artigo, empregamos somente o conceito de enquadramento para o estudo do discurso em sala de aula, embora tenhamos consciência de que, como afirmam Straehler-Pool e Gellert:

É a análise da interação entre o enquadramento e a classificação o que nos permite detectar os mecanismos interativos que promovem a reprodução de desigualdades no nível da sala de aula (Straheler-Pool, \& Gellert, 2013, p. 329).

A ausência da análise da classificação permanece como uma lacuna em nosso estudo, a qual pretendemos preencher com outro trabalho, pois ainda carecemos dos instrumentos para esta tarefa.

Por fim, chamamos a atenção para que a formação de professores de Ciências aprofunde as questões associadas com o discurso em sala de aula ecom o desenvolvimento 
de práticas pedagógicas mais favoráveis às interações entre professores e alunos, de modo a incorporar estratégias de estímulo ao diálogo que favoreçam a aquisição da linguagem científica e dos conceitos pelos aprendizes, considerando a sua totalidade em sala e não apenas alguns poucos estudantes.

\section{Agradecimentos}

Ao CNPq, a Fapesb e a Capes.

\section{Referências}

Aguiar Jr. O. G., Mortimer, E. F., \& Scott, P. H. (2006). As perguntas dos estudantes e seus desdobramentos no discurso da sala de aula de ciências. In Resumos do X Encontro de Pesquisa em Ensino de Física. Londrina, PR.

Aguiar Jr., O. G., Mendonça, D. H., \& Silva, N.S. (2007). Análise do discurso em uma sala de aula de Ciências: a postura do professor e a participação dos estudantes. In Anais do VI Encontro Nacional de Pesquisa em Educação em Ciências. Florianópolis, SC.

Altet, M. (2000). Análise das práticas dos professores e das situações pedagógicas. Porto: Porto Editora.

Andrade, G. M. P. C., \& Mozzer, N. B. (2016). Análise dos questionamentos do professor em atividades fundamentadas em modelagem analógica. Revista Brasileira de Pesquisa em Educação em Ciências, 16(3), 825-850.

Bachelard, G. (1996). A formação do espírito científico. Rio de Janeiro: Contraponto.

Bernstein, B. (1988). Poder, educación y conciencia. Sociología de la transmisión cultural. Santiago: CIDE.

Bernstein, B. (2001). La estructura del discurso pedagógico, 4a ed. Madrid: Morata.

Bleicher, R. E., Tobin, K.G., \& McRobbie, C. J. (2003). Opportunities to talk Science in a high school chemistry classroom. Research in Science Education, 33(3), 319-339. https:// doi.org/10.1023\%2FA\%3A1025480311414

Chin, C. (2006). Classroom interaction in Science: teacher questioning and feedback to students' responses. International Journal of Science Education, 28(11), 1315-1346. https://doi.org/10.1080/09500690600621100

Erdogan, I., \& Campbell, T. (2008). Teacher questioning and interaction patterns in classrooms facilitated with different levels of constructivist teaching practices. International Journal of Science Education, 30(14), 1891-1914. https://doi. org/10.1080/09500690701587028

Jackson, P. W. (2002). Prácticas de la enseñanza. Buenos Aires: Amorrortu. 
Kawalkar, A., \& Vijapurkar, J. Scaffolding science talk: the role of teachers' questions in the inquiry classroom. International Journal of Science Education, 35(12), 2004-2027. https://doi.org/10.1080/09500693.2011.604684

Lee, O. (2005). Science education with English language learners: synthesis and research agenda. Review of Educational Research, 75(4), 491-530. https://doi. org/10.3102/00346543075004491

Lemke, J. (1997). Aprender a hablar ciencia: lenguaje, aprendizaje y valores. Barcelona: Paidós.

Magalhães, S. C., Mortimer, E. F. \& Silva, A. F. (2016). Uma análise da relação entre a abordagem comunicativa e os tipos de perguntas de duas professoras da Educação Básica nas aulas de termoquímica. In Anais do XVIII Encontro Nacional de Ensino de Química. Florianópolis, SC.

Mehan, H. (1979). Learning lessons. Social organization in the classroom. Cambridge: Harvard University Press.

Moore, R., \& Muller, J. (2003). O crescimento do conhecimento e a lacuna discursiva. Educação \& Sociedade, 24(85), 1343-1360.

Morais, A. M. (2002). Basil Bernstein at the microlevel of classroom. British Journal of Sociology of Education, 23(4), 559-569.

Morais, A. M., \& Miranda, C. (1996). Understanding teachers' evaluation criteria: a condition for success in Science classes. Journal of Research in Science Teaching. 33(6), 601-624.

Morais, A. M., \& Neves, I. P. (2001). Pedagogic social contexts: studies for a sociology of learning. In A. M. Morais, I. Neves, B. Davies, \& H. Daniels (Eds.). Towards a sociology of pedagogy: the contribution of Basil Bernstein to research (pp. 185-221). New York: Peter Lang.

Mortimer, E. F., Massicame, T., Buty, C., \& Tiberghien, A. (2007). Uma metodologia para caracterizar os gêneros de discurso como tipos de estratégias enunciativas nas aulas de ciências. In R., Nardi, A pesquisa em ensino de Ciência no Brasil: alguns recortes (pp. 53-94). São Paulo, SP: Escrituras.

Neiman, G., \& Quaranta, G. (2007). Los estudios de caso en la investigación sociológica. In I.V., Gialdino, (Coord.), Estrategias de investigación cualitativa (pp. 213-235). Buenos Aires: Gedisa.

Quílez-Pardo, J. (2016). El lenguaje de la ciencia como obstáculo de aprendizaje de los conocimientos científicos y propuestas para superarlo. Revista Brasileira de Pesquisa em Educação em Ciências, 16(2), 449-476. 
Silva, C. P. (2015). Interações discursivas em aulas de Química: relações com o engajamento dos alunos. (Dissertação de Mestrado em Ensino de Ciências e Matemática). Universidade Federal de Sergipe, Aracaju.

Schein, Z. P., \& Coelho, S. M. (2006). O papel do questionamento: intervenções do professor e do aluno na construção do conhecimento. Caderno Brasileiro de Ensino de Física, 23(1), 68-92.

Specht, C. C., Ribeiro, M. E. M., \& Ramos, M. G. (2017). Estudo das perguntas de professores e estudantes em aulas de Química. Revista Thema, 14, 225-242. http:// dx.doi.org/10.15536/thema.14.2017.225-242.395

Souza, G. M. (2015). A influência do contexto social sobre a prática pedagógica de Química: uma análise na perspectiva de Basil Bernstein. (Dissertação de Mestrado em Educação Científica e Formação de Professores de Ciências e Matemática). Universidade Estadual do Sudoeste da Bahia, Jequié.

Straehler-Pool, H., Gellert, U. (2013). Towards a Bernsteinian language of description for mathematics classroom discourse. British Journal of Sociology of Education, 34(3), 313-332.

Tobin, K. (1987). The role of waiting time in higher cognitive level learning. Review of Educational Research, 57(1), 69-95. https://doi.org/10.3102/00346543057001069

Torres, J., Almeida, A., \& Vasconcelos, C. (2015). Questionamentos em manuais escolares: um estudo no âmbito das Ciências Naturais. Ciência \& Educação, 21(3), 655671. https://doi.org/10.1590/1516-731320150030009

Tytler, R., Aranda, G. (2015). Expert teachers' discursive moves in Science classroom interactive talk. International Journal of Science and Mathematics Education, 3(2), 425446.

van Zee, E., \& Minstrell, J. (1997). Using questioning to guide student thinking. Journal of the Learning Sciences, 6(2), 227-269. https://doi.org/10.1207/s15327809jls0602_3

Yin, R. K. (2005). Estudo de caso: planejamento e métodos, $3^{\text {a }}$ ed.. Porto Alegre: Bookman. 


\section{Rivaldo Lopes da Silva}

${ }^{\circ}$ http://orcid.org/0000-0002-8587-457X

Universidade Estadual do Sudoeste da Bahia Programa de Pós Graduação em Educação Científica e Formação de

Professores de Ciências e Matemática Jequié, Brasil rivaldo.lopesdasilva31@gmail.com

\section{Geovânia Moreira Souza}

${ }^{-1}$ http://orcid.org/0000-0002-2263-7710

Universidade Estadual do Sudoeste da Bahia Programa de Pós Graduação em Educação Científica e Formação de Professores de Ciências e Matemática Jequié, Brasil geovania.quimica@hotmail.com

\section{Bruno Ferreira dos Santos}

${ }^{\oplus}$ https://orcid.org/0000-0002-6168-2303 Universidade Estadual do Sudoeste da Bahia Departamento de Ciências e Tecnologias Jequié, Brasil bf-santos@uol.com.br 